УДК 549.01:550.4(571.54/.55)

\title{
ВЛИЯНИЕ ГЕОЛОГИЧЕСКИХ ФАКТОРОВ НА РАСПРЕДЕЛЕНИЕ УРАНА И ТОРИЯ В СОЛЕВЫХ ОТЛОЖЕНИЯХ ПИТЬЕВЫХ ВОД (РЕСПУБЛИКА БАШКОРТОСТАН)
}

\author{
Фархутдинов Исхак Мансурович1, \\ iskhakgeo@gmail.com
}

\section{Соктоев Булат Ринчинович2, bulatsoktoev@tpu.ru}

Рихванов Леонид Петрович², rikhvanov@tpu.ru

\section{Фархутдинов Анвар Мансурович1, anvarfarh@mail.ru}

\author{
Злобина Анастасия Николаевна ${ }^{1,2}$, \\ anastasiyazl@mail.ru
}

\author{
Исмагилов Рустем Айратович3,1, \\ rustem_ismagilov@bk.ru
}

Никонов Владимир Николаевич4,
nikon-ufa@mail.ru

\section{Белан Лариса Николаевна 4 , belan77767@mail.ru}

\footnotetext{
1 Башкирский государственный университет, Россия, 450076, г. Уфра, ул. Заки Валиди, 32.

2 Национальный исследовательский Томский политехнический университет, Россия, 634050, г. Томск, пр. Ленина, 30.

3 Институт геологии УФИЦ РАН, Россия, 450000, г. Уфа, ул. К. Маркса, 16/2.

4 Научно-исследовательский институт безопасности жизнедеятельности, Россия, 450005, г. Уфра, ул. 8 Марта, 12/1.
}

\begin{abstract}
Актуальность исследования обусловлена необходимостью выявления источников поступления естественных радиоактивных элементов в питьевую воду, а также возможностью использования солевых отложений питьевых вод (накипи) в геохимических и экологических исследованиях. Наличие на территории Башкортостана различных геологических структур (горная область, предгорньй прогиб, платформа), а также большое разнообразие горных пород различного возраста и состава (вулканогенные, интрузивные, осадочные, метаморфические) благоприятствует данным исследованиям и обуславливает большое разнообразие микроэлементного профиля местности.

Цель: оценка содержания и пространственного распределения радиоактивных элементов в солевых отложениях питьевых вод (накипи) на территории Республики Башкортостан.

Объекты. Проанализированы данные по содержанию U и Th в 467 пробах солевых отложений питьевых вод (накипи) из 267 населенных пунктов Республики Башкортостан. Пробы отобраны из различной посуды (эмалированные и электрические чайники, кастрюли, котлы, самовары), которая используется для кипячения воды из иентрализованных и индивидуальных (скважины, колодиы, ручьи) источников водоснабжения.

Методы. Для анализа содержания U и Th использовался метод инструментального нейтронно-активационного анализа на базе исследовательского ядерного реактора ИРТ-Т ТПУ. Обработка данных проводилась с использованием программных пакетов Statistica 8.0 и Microsoft Excel 2013. Построение карт пространственного распределения естественных радиоактивных элементов в солевых отложениях питьевых вод проведено с помощью программы ArcGIS 10.2 в модуле Geostatistical Analyst методом обратных расстояний.

Результаты. Полученные данные позволяют говорить о неравномерном распределении естественных радиоактивных элементов (U, Th) в солевых отложениях на территории Республики Башкортостан. Региональный фон концентрации U и Th отличается пониженными значениями. Вариации их содержания определяются воздействием как природных, так и антропогенных факторов. Закономерности распределения $U$ в пробах накипи хорошо согласуются с особенностями геологического строения территории. В пределах платформенной части распределение $U$ является более равномерным по площади, чем в горной части республики, что отражает сравнительную однородность геологических и тектонических условий. По результатам картирования выделено четыре зоны повышенного содержания $U$ в образцах солевых отложений: зауральская, уральская, западная и южная. В пространственном распределении Тh не выявлено четкой корреляционной связи с особенностями геологического строения и металлогении территории. Выделены три зоны: северная, центральная и юго-восточная. Отмечены отрицательные аномалии содержания Th, территориально совпадающие с крупными горнодобывающими центрами. Показатель Th/U отношения характеризуется низким значением для всей территории Башкортостана - 0,002. При этом положительные аномалии данного показателя зафиксированы в северной и юго-восточной частях республики, где они обусловлены, преимущественно, геологической составляющей.
\end{abstract}

\section{Ключевые слова:}

Уран, торий, антропогенные карбонаты, геоэкология, торий-урановое отношение,

Республика Башкортостан, Южный Урал, геохимия, радиоактивные элементы, питьевые воды. 


\section{Введение}

Карбонатные отложения занимают около 15 \% поверхности суши, существенная часть осадочного чехла платформ и морских осадков представлена данными породами $[1,2]$. Исследование различных геологических процессов (палеосейсмических и палеоклиматических событий, тектонической активизации и др.) в науках о Земле ведется в том числе за счет изучения осадочных карбонатных образований (травертины, гейзериты, сталактиты, сталагмиты) [3-9 и др.].

Содержание U и Th в верхней части континентальной коры по современным оценкам колеблется в следующих пределах: Th - 8,6-10,7 мг/кг, U 1,5-2,8 мг/кг $[10,11]$. Средний уровень данных элементов в осадочных карбонатных породах составляет 4,3 мг/кг для Th и 2,2 мг/кг для U [11]. Вариации содержания Th и U, а также их отношения (Th/U, U/Th) часто являются предметом исследований для выявления источников поступления, а также смены геохимических обстановок вследствие различных геохимических свойств данных химических элементов (прежде всего, из-за поливалентности U) [12-16].

Карбонатные отложения также широко распространены и в антропогенных условиях, например в системах транспортировки и распределения воды [17, 18 и др.]. Также они накапливаются в бытовой теплообменной аппаратуре. В этом случае образование карбонатов (накипи) связано с достижением состояния пересыщения по $\mathrm{CaCO}_{3}$ по мере увеличения температуры во время кипячения воды в электрическом чайнике (кастрюле или котле).

Изучение элементного (в том числе Th и U) состава таких отложений проводится на кафедре геоэкологии и геохимии (в настоящее время - отделение геологии) Томского политехнического университета (ТПУ), начиная с 1990-х гг. [19, 20 и др.]. За этот период отобрано более 1000 проб на территории Томской, Кемеровской, Иркутской, Челябинской областей, Республик Бурятия и Башкортостан, Павлодарской области Казахстана. Полученные данные по содержанию Th и U в данных отложениях свидетельствуют об их неравномерном распределении. Формирование радиогеохимической специализации данных образований связано с влиянием как природного, так и техногенного факторов. Вариации содержания радиоактивных элементов в накипи позволяют использовать их в качестве косвенного поискового критерия, в частности, на урановое оруденение. Нарушение фонового показателя $\mathrm{Th} / \mathrm{U}$ является индикаторным в антропогенно нагруженных районах, особенно в зонах функционирования объектов ядерно-топливного цикла (места проведения подземных ядерных взрывов, химические комбинаты по обогащению урана и др.) [21].

Территория Республики Башкортостан (РБ) является уникальным полигоном для геохимических исследований в связи с наличием разнообразных по составу и происхождению пород и различных нефтеи горнодобывающих, а также перерабатывающих предприятий.

\section{Материалы и методы исследования}

Территория исследования. Исследование было проведено на территории РБ - региона Европейской части России общей площадью 143600 км². Республика расположена в зоне сочленения двух крупных геологических структур. Восточная часть РБ относится к Южному Уралу, западная часть расположена на восточной окраине Восточно-Европейской платформы. Между Южным Уралом и Восточно-Европейской платформой выделяется переходная зона в виде Предуральского краевого прогиба. В горной части РБ выделяют четыре основные тектонические структуры: Башкирский мегантиклинорий, Зилаирский синклинорий, антиклинорий Уралтау, Магнитогорский синклинорий (рис. 1). Сложное геологическое строение и металлогения определяют вариации содержания химических элементов, в том числе радиоактивных. На территории республики имеется множество рудопроявлений урановой и ториевой минерализации, где уровень радиационного фона приближается к предельно допустимым значениям [22].

Наряду с природными факторами существенен вклад антропогенных: на равнинной части развита нефтегазодобывающая (запад, северо-запад, центральная часть РБ), химическая и нефтехимическая (гг. Стерлитамак, Уфа, Салават, Мелеуз, Туймазы, Октябрьский) отрасли, добыча бурого угля (юг, г. Кумертау, Южно-Уральский буроугольный бассейн). В горной и зауральской частях сосредоточены объекты горнодобывающей промышленности (добыча цветных металлов, железа, золота) (рис. 1). Вокруг предприятий данных отраслей имеются очаги кризисной и катастрофической геоэкологической обстановки [23-25 и др.].

Отбор проб. Проанализированы данные по содержанию Th и U в 467 пробах солевых отложений питьевых вод из 267 населенных пунктов РБ. Пробы отбирались в соответствии с рекомендациями [26] и с учетом опыта предыдущих исследований. Отбор проб проводился из различной посуды (эмалированные и электрические чайники, кастрюли, котлы, самовары), которая используется для кипячения воды, как из централизованных, так и индивидуальных (скважины, колодцы, ручьи) источников водоснабжения.

Аналитические методы. Анализ содержания Th и $\mathrm{U}$ проводился методом инструментального нейтронно-активационного анализа (ИНАА) с использованием исследовательского ядерного реактора ИРТ-Т ТПУ (ядерно-геохимическая лаборатория Международного инновационного научно-образовательного центра «Урановая геология», аттестат аккредитации № RA.RU.21АБ27 от 08.04.2015 г., аналитики A.Ф. Судыко, Л.Ф. Богутская). Данный метод эффективен для определения радиоактивных элементов [27, 28].

Обработка результатов. Для обработки данных применяли программные пакеты Statistica 8.0 и Microsoft Excel 2013. При статистической обработке полученных результатов определялись: среднее арифметическое значение, стандартная ошибка, сред- 
нее геометрическое значение, медиана, мода, минимальное и максимальные значения, стандартное отклонение, коэффициент вариации, асимметрия, эксцесс и их стандартные ошибки. В расчет средних содержаний не были включены «ураганные пробы», однако данные пробы показаны в разбросах частных значений. Тесты Лиллиефорса, КолмогороваСмирнова и Хи-квадрат были применены для проверки на нормальность распределения элементов в выборке. Накипь из воды озера Байкал, полученная авторами (содержание Th - 0,384 мг/кг, U - 4,51 мг/кг), и кларк осадочных карбонатных пород [11] были использованы как фоновые показатели для расчета коэффициентов концентрации и определения геохимической специализации.

Построение карт пространственного распределения естественных радиоактивных элементов проведено с помощью программы ArcGIS 10.2 в модуле Geostatistical Analyst методом обратных расстояний. Шаг в классификации выбран автоматический для каждой карты согласно методу классификации «Геометрический интервал».

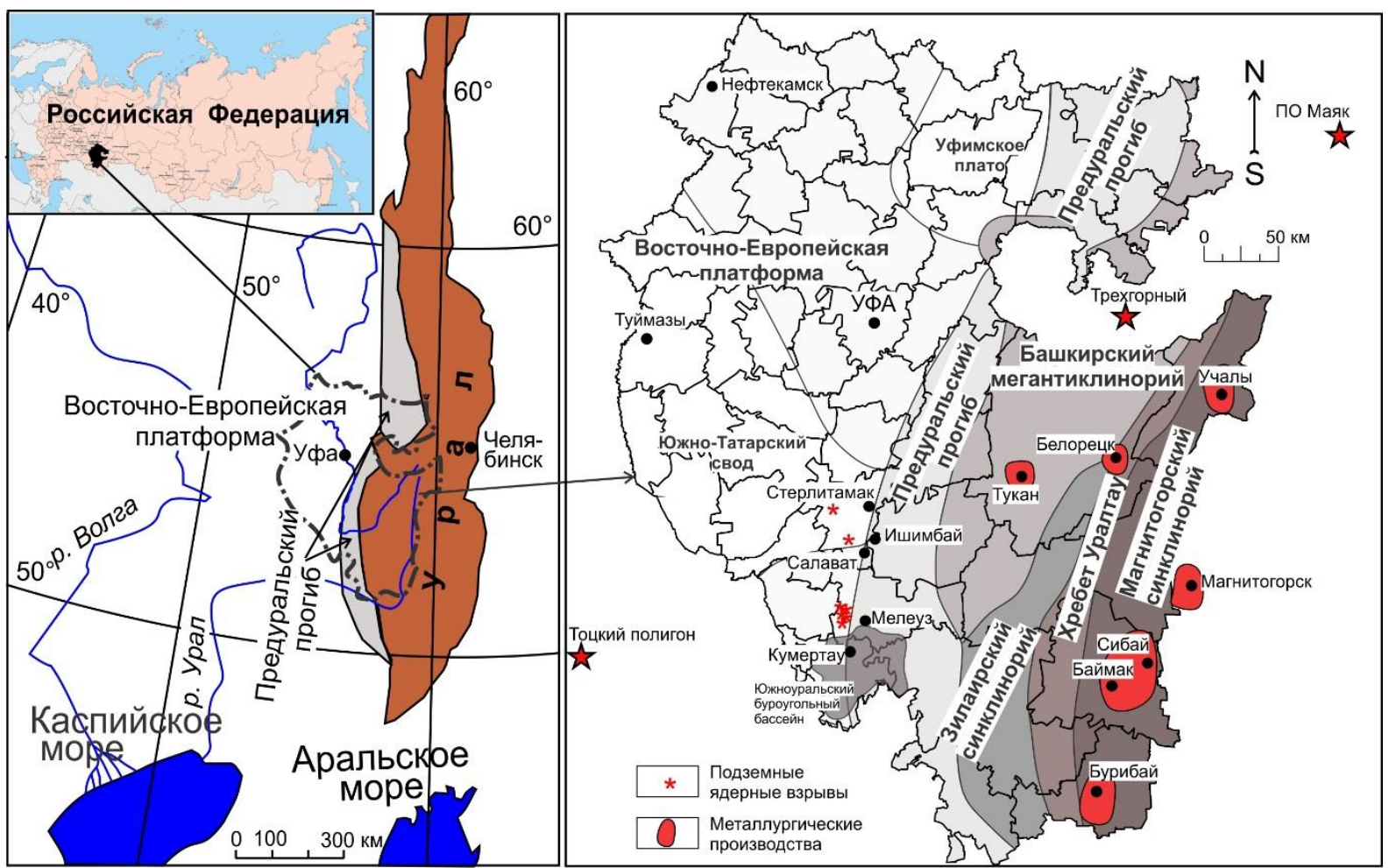

Рис. 1. Обзорная геоэкологическая карта территории исследования

Fig. 1. Overview geoecological map of the study area

\section{Результаты и их обсуждение}

Обработанные аналитические данные представлены в таблице. Ввиду того, что распределение Th и U отличается от нормального, в качестве среднего значения выбрана медиана.

При сравнении с фоновыми показателями и данными по другим регионам (Томская, Кемеровская, Иркутская, Челябинская области, Республики Бурятия, Алтай; Павлодарская область Казахстана) обнаружено, что изучаемые отложения на территории РБ характеризуются пониженными содержаниями естественных радиоактивных элементов: средняя концентрация Тh минимальна среди всех изученных регионов, среднее содержание U ниже только на территории Томской области $(1,9$ мг/кг). По пониженному значению $\mathrm{Th} / \mathrm{U}$ отношения $(0,002)$ территория республики выделяется среди всех изученных нами регионов [21].
Таблица. Статистические параметры содержсания Th и $U$ (мг/кг) в солевых отложениях питьевых вод на территории Республики Башкортостан

Table. Statistical parameters of $T h$ and $U(\mathrm{mg} / \mathrm{kg})$ content in salt sediments (scale) on the territory of the Republic of Bashkortostan

\begin{tabular}{|l|c|c|}
\hline \multicolumn{1}{|c|}{$\begin{array}{c}\text { Статистические параметры } \\
\text { Statistical parameters }\end{array}$} & $\mathrm{Th}$ & $\mathrm{U}$ \\
\hline Среднее арифметическое/Arithmetic mean & 0,03 & 8,5 \\
\hline Стандартная ошибка/Standard error & 0,004 & 0,4 \\
\hline Среднее геометрическое/Geometric mean & 0,01 & 4,7 \\
\hline Медиана/Median & 0,01 & 5,3 \\
\hline Мода/Mоde & 0,003 & - \\
\hline Минимум-максимум/Minimum-maximum & $0,0002-3,27$ & $0,01-61,0$ \\
\hline $\begin{array}{l}\text { Стандартное отклонение } \\
\text { Standard deviation }\end{array}$ & 0,08 & 9,2 \\
\hline $\begin{array}{l}\text { Коэффициент вариации } \\
\text { Соеfficient of variation }\end{array}$ & 449 & 112 \\
\hline Асимметрия/Skewness & 5,6 & 2,0 \\
\hline Эксцесс/Kurtosis & 36,6 & 4,2 \\
\hline
\end{tabular}

Примечание/Note: «-»- значение не определено/value is not defined. 
Пространственное распределение как Th и U, так и Th/U в солевых отложениях питьевых вод на территории РБ носит неравномерный характер. Сразу следует отметить хорошее согласование распределения U c особенностями геологического строения и в ряде случаев с техногенными источниками, в то время как для Тh такой четкой корреляционной связи не выявлено.
Пространственное распределение U. По результатам построения карты пространственного распределения U в пробах накипи нами выделены четыре зоны со сравнительно повышенным содержанием данного химического элемента: в пределах складчатой части зауральская, уральская, в пределах платформенной части - западная и южная (рис. 2).

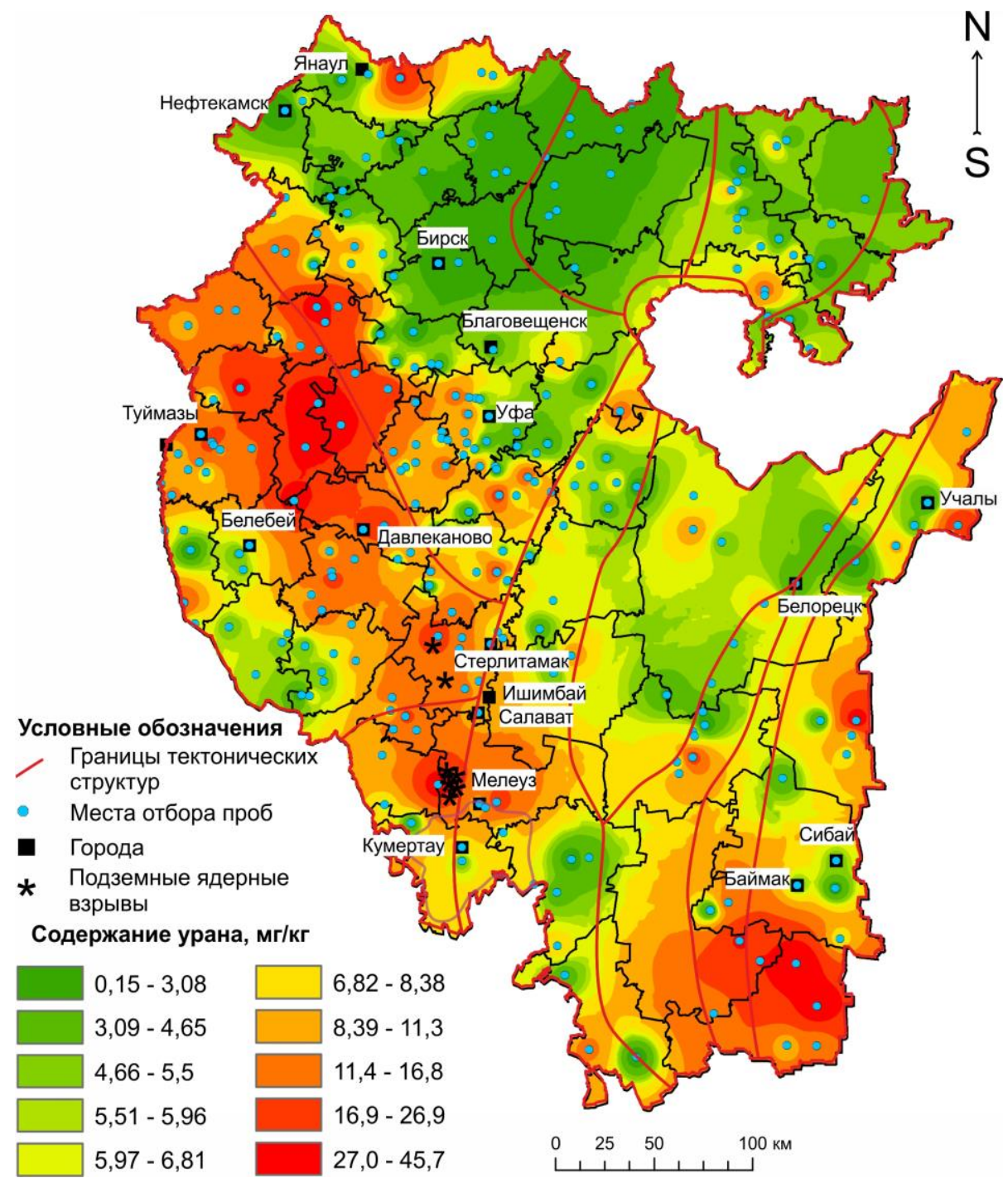

Pис. 2. Карта пространственного распределения урана в солевых отложениях питьевых вод (накипи) на территории Республики Башкортостан. Метод классификации «геометрический интервал»

Fig. 2. Map of uranium spatial distribution in salt sediments (scale) on the territory of the Republic of Bashkortostan. Classification method "geometric interval»

Зауральская зона. Повышенное содержание U (от 22 до $45 \mathrm{mг} / к г$ ) выявлено в Абзелиловском, Зилаирском, Учалинском и Хайбуллинском районах (рис. 2). Максимальные концентрации (до 45 мг/кг) приурочены в основном к площади развития метаморфических сланцев максютовского комплекса антиклинория Уралтау, к девонским вулканогенно-осадочным толщам запада Магнитогорской мегазоны (синклинория) (ирендыкская свита - базальты, андезибазальты, риодациты, кремнисто-глинистые сланцы, улутауская свита - вулканомиктовые песчаники, туффиты, кремнистые сланцы, андезибазальты, андезиты, риодациты и их туфы).
В южной части Башкирского Зауралья обширное поле повышенных концентраций U совпадает с Таналыкской депрессией, на поверхности частично перекрытой юрскими терригенными отложениями. Ореолы на востоке Абзелиловского района (до 36,2 мг/кг) приурочены к известнякам кизильской свиты $\left(\mathrm{C}_{1}-\mathrm{C}_{2}\right)$, в которых с зонами ожелезнения и окремнения связаны урановые аномалии [22]. На территории Учалинского района аномалия связана с выходами лейкогранитов ахуново-карагайского комплекса $\left(\mathrm{C}_{2}\right)$. В целом полученные данные по зауральской зоне хорошо согласуются в данными опробования донных отложений [29]. 
Уральская зона. Аномалии повышенных содержаний U (от 10 до 23 мг/кг) выявлены в Белорецком, Бурзянском, Дуванском и Салаватском районах. Для данной зоны характерно вероятное совместное воздействие комплексов горных пород и тектонического фактора, например, в Бурзянском районе, где ореол приурочен к битуминозным известнякам $\left(\mathrm{D}_{2}\right) \mathrm{c}$ надвиговой дислокацией (Зилаирский синклинорий). Согласно шарьяжно-надвиговой теории тектонические дислокации являются одним из основных факторов, повышающих мобильность элементов в горных породах [30, 31].

В Башкирском мегантиклинории наблюдается приуроченность высоких концентраций U к глауконитовым сланцам и алевролитам инзерской свиты $\left(\mathrm{RF}_{3}\right)$. В качестве дополнительных источников поступления данного химического элемента могут выступать месторождения бурых железняков и черносланцевые толщи рифейского возраста, с которыми сопряжены повышенные концентрации $\mathrm{U}(\mathrm{Ra})$ и $\mathrm{Rn}$ в подземных водах и высокая активность Rn в почвенном воздухе [22].

Для населенных пунктов, расположенных в пределах Предуральского краевого прогиба (например, Дуванский район), аномалии U связаны с фосфатизированной кровлей артинско-сакмарских известняковых рифовых массивов, в которых ранее отмечены содержания $\mathrm{U}-0,01-0,04$ \%, мощность экспозиционной дозы (МЭД) - до 300 мкр/ч (Ярославская, Митрофановская и другие аномалии). Необходимо отметить аномалии $\mathrm{U}$, которые выявлены в зоне сочленения складчатого Урала и Предуральского прогиба (населенные пункты Янгантау, Комсомол Салаватского района), где на поверхность изливаются многочисленные радоновые и сероводородные источники, в том числе термальный источник Янган-Тау и источник Кургазак. В данном случае, вероятно, тектонический фактор сочетается с геохимическим, обусловленным широким развитием битуминозных пород (содержание U - до 0,02 \%) [22].

Западная зона. По сравнению с горно-складчатой частью РБ пространственное распределение $\mathrm{U}$ в пределах юго-восточной части Восточно-Европейской платформы характеризуется более равномерным распределением, что обусловлено относительной однородностью геологических и тектонических обстановок. В то же время в западной зоне нами выявлена зона, генезис которой имеет природно-техногенный характер: в геологическом отношении она соответствует Шаранскому и Туймазинскому выступам кристаллического гранито-гнейсового фундамента и их восточным склонам (глубины залегания - от 2,5 до 6 км), а также областям распространения пермских красноцветных толщ уфимского яруса $\left(\mathrm{P}_{1}\right)$. Данный район одновременно является центром нефтегазодобывающей промышленности РБ. Интенсивное отложение радиоактивных осадков возможно на установках подготовки нефти и в технологическом оборудовании (МЭД - до 3000 мкР/ч) [32]. Обращает также на себя внимание пространственная сопряженность данной зоны накопления урана с площадью развития медистых песчаников гидрогенного генезиса в пермских красноцветных толщах $[33,34]$.

Южная зона. В пределах данной зоны повышенные концентрации U отмечены в пробах из населенных пунктов Кугарчинского, Куюргазинского и Мелеузовского районов. В этом случае мы также предполагаем природно-техногенный генезис, связанный, прежде всего, с разработкой месторождений ЮжноУральского буроугольного бассейна. Для углей характерны высокие адсорбционные свойства касательно широкого спектра химических элементов, в том числе и радиоактивных [35-39]. Для углей ЮжноУральского буроугольного бассейна также известна повышенная радиоактивность: на Ушкатлинском, Ново-Казанском, Маячном месторождениях содержание U в угле достигает $0,1 \%$, в золе - $1 \%$ [22].

К дополнительным антропогенным факторам, вероятно, следует отнести подземные ядерные взрывы, которые были проведены в данной части РБ с 1965 по 1984 гг. для создания подземных хранилищ захоронения промышленных отходов (район г. Стерлитамак, г. Салават) и интенсификации добычи углеводородов (район г. Мелеуз, Грачевское месторождение). Замеры радиационного фона показывают наличие аномалии - до 250 мкР/ч [40]. Повышенные содержания U в изучаемых нами отложениях хорошо согласуются с данными по почвам в этом районе [24]. Однако данный вопрос требует дальнейших исследований, прежде всего, изучения изотопных отношений для более точного определения источника $\mathrm{U}$.

Из отрицательных аномалий пространственного распределения U следует отметить территорию, приуроченную к Уфимскому плато, сложенному преимущественно известняками, а также зону наиболее крупного Арланского месторождения нефти, где причиной низкого уровня $\mathrm{U}$ может являться погружение кристаллического фундамента в Камско-Бельском авлакогене на глубину более 10 км.

Пространственное распределение Th. Как уже ранее упоминалось, в пространственном распределении Th не выявлено четкой корреляционной связи с особенностями геологического строения и металлогении территории РБ (рис. 3).

По результатам исследования выявлены ореолы максимальных концентраций $\mathrm{Th}$, приуроченные к центральной (Благовещенский, Иглинский, Нуримановский, Уфимский районы), северной (Аскинский, Балтачевский, Краснокамский районы) и юговосточной (Абзелиловский, Баймакский районы) части республики.

Ореол повышенного содержания Th в юговосточной части РБ может быть связан с развитием углистых, хлорит-актинолитовых сланцев суванякского комплекса антиклинория Уралтау. В центральной части одним из возможных источников поступления Th могут являться углистые сланцы $\left(\mathrm{C}_{3}\right)$ и связанные с ними элювиально-делювиальные фосфатизированные глины, в которых отмечены содержания Th до $0,1 \%$ [22]. 


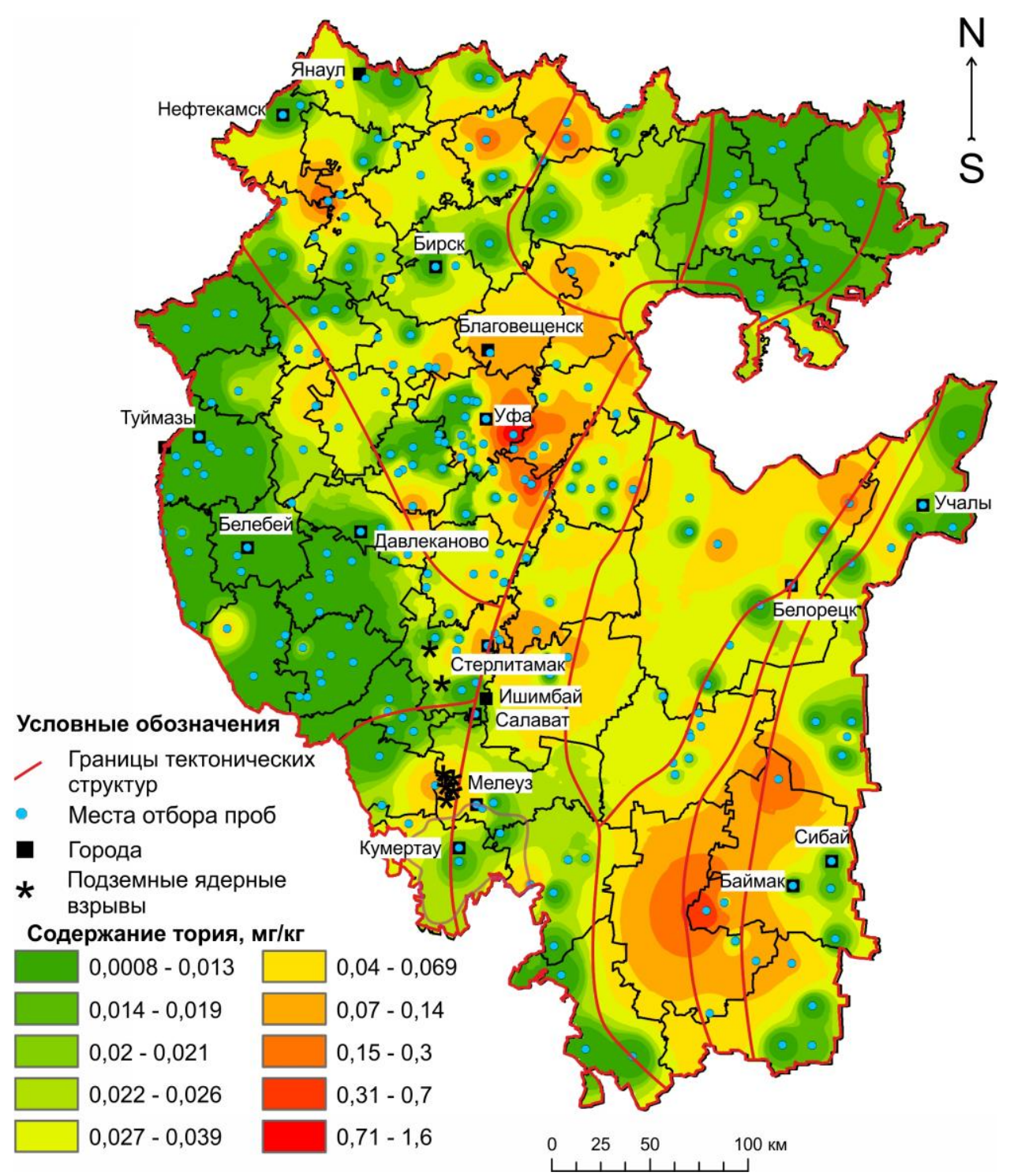

Pис. 3. Карта пространственного распределения тория в солевых отложениях питьевых вод (накипи) на территории Республики Башкортостан. Метод классификации «геометрический интервал»

Fig. 3. Map of thorium spatial distribution in salt sediments (scale) on the territory of the Republic of Bashkortostan. Classification method «geometric interval»

Пониженными содержаниями Тh в солевых отложениях отличается западная и северо-восточная части республики. Из интересных моментов следует отметить отрицательные аномалии, выявленные в районах расположения крупных горнодобывающих (гг. Баймак, Белорецк, Кумертау, Сибай, Учалы), нефтедобывающих (гг. Нефтекамск, Туймазы) и нефтехимических (гг. Ишимбай, Салават) центров РБ.

Пространственное распределение Th/U отношения $\mathrm{Th} / \mathrm{U}$ отношение в пределах республики в солевых отложениях питьевых вод меняется в широких интервалах: от 0,00008 до 1,36 (рис. 4). Несмотря на разброс значений в пять порядков, пространственное распределение данного показателя имеет преимущественно однородный характер в солевых отложениях питьевых вод на территории РБ. Большая часть территории региона характеризуется значениями $\mathrm{Th} / \mathrm{U}$ отношения в изучаемых отложениях ниже 0,02 . Минимальные значения данного показателя отмечаются в платформен- ной части республики. Ореолы повышенных значений $\mathrm{Th} / \mathrm{U}$ отношения приурочены к Зилаирскому синклинорию и антиклинорию Уралтау - в восточной части, и к Уфимскому плато - в северной части республики.

\section{Заключение}

Таким образом, полученные данные позволяют говорить о неравномерном распределении естественных радиоактивных элементов (Th, U) в солевых отложениях питьевых вод (накипи) на территории Республики Башкортостан. Среднее содержание Тh $(0,01$ мг/кг) и U $(5,3$ мг/кг) в накипи на территории РБ характеризуется как низкое по сравнению с пробами из других изученных регионов - Томской, Кемеровской, Иркутской, Челябинской областей, Республик Бурятия, Алтай (Россия); Павлодарской области (Казахстан). Вариации их содержания в изучаемых образованиях определяются воздействием природных и антропогенных факторов. 


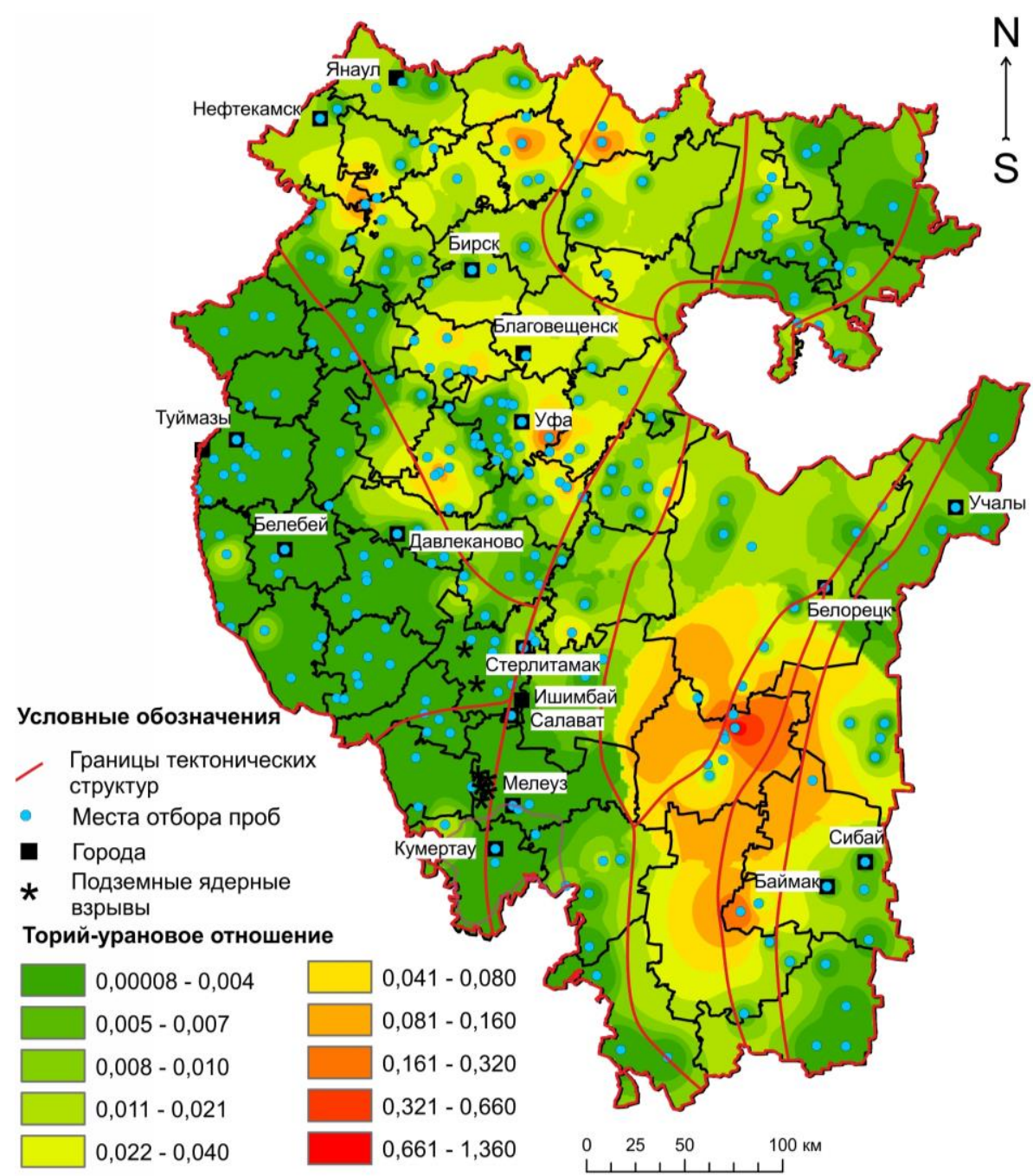

Pис. 4. Карта пространственного распределения торий-уранового отношения в солевых отложениях (накипи) на территории Республики Башкортостан. Метод классификации «геометрический интервал» с округлением до тысячных

Fig. 4. Map of thorium-uranium ratio spatial distribution in salt sediments (scale) on the territory of the Republic of Bashkortostan. The classification method is the "geometric interval» rounded-off to thousandths

Закономерности распределения U в пробах накипи хорошо согласуются с особенностями геологического строения территории. При этом в отдельных случаях, вероятно, на природный фактор накладывается и техногенный. В пределах платформенной части распределение $\mathrm{U}$ является более равномерным по площади, чем в горной части республики, что отражает сравнительную однородность геологических и тектонических условий. По результатам картирования выделено четыре зоны повышенного содержания U в образцах солевых карбонатных отложений: зауральская, уральская, западная и южная.

B платформенной части аномальная зона U совпадает с площадью добычи и переработки нефти, а также с территорией развития медистых песчаников. Это наводит на мысль о связи аномалий $U$ с природной и техногенной миграцией углеводородов, а также с гидрогенным рудогенезом в пермских красноцветах. Южная аномальная зона в Предуралье приурочена к площади развития и разработки миоценовых бурых углей. В Башкирском Зауралье аномалии связаны в основном с девонскими и карбоновыми вулканогенно-осадочными, карбонатными, интрузивными формациями, а также юрским чехлом терригенных морских отложений.

В пространственном распределении Тh не выявлено четкой корреляционной связи с особенностями геологического строения и металлогении территории. Выделены три зоны повышенных содержаний данного элемента в солевых отложениях питьевых вод: северная, центральная и юго-восточная.

Показатель $\mathrm{Th} / \mathrm{U}$ отношения также характеризуется низким значением для всей территории РБ - 0,002. При этом положительные аномалии данного показателя зафиксированы в северной и юго-восточной частях республики, где они обусловлены, преимущественно, геологической составляющей.

Научные исследования выполнены в рамках программы повышения конкурентоспособности ТПУ среди ведущих мировых исследовательских иентров. 


\section{СПИСОК ЛИТЕРАТУРЫ}

1. Карбонаты: минералогия и химия / пер. с англ. / под ред. Р.Дж. Ридера. - М.: Мир, 1987. - 496 с.

2. Morse J.W., Arvidson R.S., Luttge A. Calcium carbonate for mation and dissolution // Chemical Reviews. - 2007. - V. 107. P. 342-381.

3. Pentecost A. Travertine. - Berlin; Heidelberg: Springer-Verlag, 2005. $-445 \mathrm{p}$.

4. Fairchild I.J., Treble P.C. Trace elements in speleothems as recorders of environmental change // Quaternary Science Reviews. 2009. - V. 28. - 449-468.

5. Tanner L.H. Continental carbonates as indicators of paleoclimate // Developments in Sedimentology. - 2010. - V. 62. - P. 179-214.

6. Geochemistry of limestones deposited in various plate tectonic settings / K.-J. Zhang, Q.-H. Li, L.-L. Yan, L. Zeng, L. Lu, Y.-X. Zhang, J. Hui, X. Jin, X.-C. Tang // Earth-Science Reviews. - 2017. - V. 167. - P. 27-46.

7. Mineralogical-geochemical features of travertines of the modern continental hydrotherms: A G-1 well, Tunka depression, Baika rift zone / B.R. Soktoev, L.P. Rikhvanov, S.S. Ilenok, N.V. Baranovskaya, T.T. Taisaev // Geology of Ore Deposits. - 2015. V. 57. - № 4. - P. 331-347.

8. Origins of elements building travertine and tufa: New perspectives provided by isotopic and geochemical tracers / P.-A. Teboul, C. Durlet, E.C. Gaucher, A. Virgone, J.-P. Girard, J. Curie, B. Lopez, G.F. Camoin // Sedimentary Geology. - 2016. - V. 334. P. 97-114

9. Global travertine deposition modulated by oscillations in climate / J.W. Ricketts, L. Ma, A.E. Wagler, V.H. Garcia // Journal of Quaternary Science. - 2019. URL: https://doi.org/10.1002/jqs.3144 (дата обращения: 10.11.2019).

10. Rudnick R.L., Gao S. Composition of the continental crust // Treatise on Geochemistry. - 2014. - V. 4. - P. 1-51. URL https://www.researchgate.net/publication/234288836_Composition _of_the_Continental_Crust_Treatise_Geochem_31-64 (дата обращения: 10.11.2019).

11. Григорьев Н.А. Распределение химических элементов в верхней части континентальной коры - Екатеринбург: УрО РАН, 2009. - 382 c.

12. Смыслов А.А. Уран и торий в земной коре. - Л.: Наука, 1974. $-231 \mathrm{c}$.

13. Евсеева Л.С., Перельман А.И., Иванов К.Е. Геохимия урана в зоне гипергенеза. - М.: Атомиздат, 1974. - 278 с.

14. Allègre C.J., Dupré B., Lewin E. Thorium/uranium ratio of the Earth // Chemical Geology - 1986. - V. 56. - № 3-4 - P. 219-227.

15. Earth's chondritic Th/U: negligible fractionation during accretion, core formation, and crust-mantle differentiation / S.A. Wipperfurth, M. Guo, O. Šrámek, W.F. McDonough // Earth and Planetary Science Letters. - 2018. - V. 498. - P. 196-202.

16. Global atmospheric oxygen variations recorded by $\mathrm{Th} / \mathrm{U}$ systematics of igneous rocks / H. Liu, R.E. Zartman, T.R. Ireland, W. Sun // Proceedings of the National Academy of Sciences of the United States of America. - 2019. URL: https://doi.org/10.1073/pnas. 1902833116 (дата обращения: 10.11.2019).

17. Oilfield scale formation and chemical removal: a review M.S. Kamal, I. Hussein, M. Mahmoud, A.S. Sultan, M.A.S. Saad // Journal of Petroleum Science and Engineering. - 2018. - V. 171. P. 127-139.

18. A $21^{\text {st }}$-century perspective on calcium carbonate formation in potable water systems / C.S. Richards, F. Wang, W.C. Becker, M.A. Edwards // Environmental Engineering Science. - 2018. V. 35. - Iss. 3. - P. 143-158

19. Geochemical specialization of limescale of water sources illustrated by two regions in Siberia / A.E. Taphaeva, T.T. Taisaev, L.P. Rikhvanov, E.G. Yazikov, N.V. Baranovskaya // Contemporary Problems of Ecology. - 2010. - V. 3. - № 4. - P. 498-507.

20. Soktoev B.R., Rikhvanov L.P., Matveenko I.A. Mineralogical and geochemical characteristics of drinking water salt deposits // IOP Conference Series: Earth and Environmental Science. - 2015. V. 27. - Iss. 1. - Article 012042

21. Естественные радиоактивные элементы (Th, U) в солевых отложениях природных пресных вод / Б.Р. Соктоев, Л.П. Рихванов, Ш.Ж. Арынова, Н.В. Барановская // Радиоактивность и радиоактивные элементы в среде обитания человека: мате- риалы V Международной конференции. - Томск: STT, 2016. С. 599-603

22. Никонов В.Н. Природная и техногенная радиоактивность Республики Башкортостан // Уральский экологический вестник. - 2012. - № 2 (31). - С. 23-30.

23. Белан Л.Н. Геоэкологические основы природно-техногенных экосистем горнорудных районов Башкортостана: автореф. дис. ... д-ра геол.-минерал. наук. - М.: Изд-во ВИМС, 2007. - 50 с.

24. Асылбаев И.Г. Оценка геохимического состояния почв Южного Урала: автореф. дис. ... д-ра биол. наук. - Уфа: Изд-во БашГАУ, 2016. - 44 с.

25. Opekunova M.G., Somov V.V., Papyan E.E. Soil contamination in the impact zone of mining enterprises in the Bashkir Transural region // Eurasian Soil Science. - 2017. - V. 50. - P. 732-745.

26. Способ определения участков загрязнения ураном окружающей среды: пат. 2298212 Рос. Федерация. № 2005120840; заявл. 04.07.05; опубл. 27.04.07, Бюл. № 12. - 6 с.

27. Witkowska E., Szczepaniak K., Biziuk M. Some applications of neutron activation analysis: a review // Journal of Radioanalytical and Nuclear Chemistry. - 2005. - V. 265. - P. 141-150.

28. Судыко А.Ф. Определение урана, тория, скандия и некоторых редкоземельных элементов в двадцати четырех стандартных образцах сравнения инструментальным нейтронноактивационным методом // Радиоактивность и радиоактивные элементы в среде обитания человека: материалы V Международной конференции. - Томск: STT, 2016. - С. 620-624.

29. Криночкин Л.А., Шкарин А.Б. Составление геохимических основ масштаба 1:1000 000 листов N-40,41,42, P-45,52,55,57, О-38,55,56. - М.: Росгеолфонд, 2011. - 178 с.

30. Камалетдинов М.А. Новая геология (теория шарьяжей) // Геология. Известия Отделения наук о Земле и природных ресурсов Академии наук Республики Башкортостан. - 1998. № 3. - C. 10-23.

31. Murat Kamaletdinov and the struggle for acceptance of the thrustnappe theory / I.M. Farkhutdinov, R.A. Ismagilov, A.M. Farkhutdinov, L.M. Farkhutdinova // Earth Sciences History. - 2017. - V. 36. № 1. - P. 101-115.

32. Минигазимов Н.С. Охрана и рациональное использование водных ресурсов в нефтяной промышленности: автореф. дис. ... д-ра техн. наук. - Екатеринбург, 2000. - 45 с.

33. Контарь Е.С. Геолого-промышленные типы месторождений меди, цинка, свинца на Урале (геологические условия размещения, история формирования, перспективы). - Екатеринбург: УГГУ, 2013. - $199 \mathrm{c}$.

34. Геохимические особенности и условия образования медистых песчаников Оренбургского Предуралья / А.В. Волков, И.А. Новиков, А.А. Разумовский, К.Ю. Мурашов, Н.В. Сидорова // Литосфера. - 2018. - Т. 18. - № 4. - С. 593-606.

35. Geochemistry of radioactive elements $(\mathrm{U}, \mathrm{Th})$ in coal and peat of northern Asia (Siberia, Russian Far East, Kazakhstan, and Mongolia) / S.I. Arbuzov, A.V. Volostnov, L.P. Rikhvanov, A.M. Mezhibor, S.S. Ilenok // International Journal of Coal Geology. - 2011. V. 86. - P. 318-328.

36. Abundance, distribution, and modes of occurrence of uranium in Chinese coals / J. Chen, P. Chen, D. Yao, W. Huang, S. Tang, K. Wang, W. Liu, Y. Hu, B. Zhang, J. // Minerals. - 2017. V. 7. - Iss. 12. - Article 239

37. Lauer N., Vengosh A., Dai S. Naturally occurring radioactive materials in uranium-rich coals and associated coal combustion residues from China // Environmental Science and Technology. - 2017. - V. 51. - P. 13487-13493.

38. Valuable elements in Chinese coals: a review / S. Dai, X. Yan, C.R. Ward, J.C. Hower, L. Zhao, X. Wang, L. Zhao, D. Ren, R.B. Finkelman // International Geology Review. - 2018. V. 60. - P. 590-620.

39. Parzentny H.R., Rog L. The role of mineral matter in concentrating uranium and thorium in coal and combustion residues from power plants in Poland // Minerals. - 2019. - V. 9. - Iss. 5. - Article 312 .

40. Государственный доклад о состоянии природных ресурсов и окружающей среды Республики Башкортостан в 2004 году. Уфа: Министерство природных ресурсов, 2004. - 306 с.

Поступила 14.11.20192. 


\section{Информация об авторах}

Фархутдинов И.М., кандидат геолого-минералогических наук, заведующий кафедрой геологии и полезных ископаемых Географического факультета Башкирского государственного университета.

Соктоев Б.P., кандидат геолого-минералогических наук, доцент отделения геологии Инженерной школы природных ресурсов Национального исследовательского Томского политехнического университета.

Рихванов Л.П., доктор геолого-минералогических наук, профессор отделения геологии Инженерной школы природных ресурсов Национального исследовательского Томского политехнического университета.

Фархутдинов A.M., кандидат геолого-минералогических наук, доцент кафедры геологии и полезных ископаемых Географического факультета Башкирского государственного университета.

Злобина А.Н., ассистент кафедры геологии и полезных ископаемых Географического факультета Башкирского государственного университета; аспирант отделения геологии Инженерной школы природных ресурсов Национального исследовательского Томского политехнического университета.

Исмагилов P.A., кандидат геолого-минералогических наук, старший научный сотрудник Института геологии УФИЦ РАН; доцент кафедры геофизики Башкирского государственного университета.

Никонов В.H., кандидат геолого-минералогических наук, старший научный сотрудник Научноисследовательского института безопасности жизнедеятельности.

Белан Л.Н., доктор геолого-минералогических наук, директор Научно-исследовательского института безопасности жизнедеятельности. 
UDC 549.01:550.4

\section{INFLUENCE OF GEOLOGICAL FACTORS ON URANIUM AND THORIUM DISTRIBUTION IN DRINKING WATER SALT DEPOSITS (REPUBLIC OF BASHKORTOSTAN)}

\author{
Iskhak M. Farkhutdinov ${ }^{1}$, \\ iskhakgeo@gmail.com
}

\author{
Bulat R. Soktoev², \\ bulatsoktoev@tpu.ru \\ Leonid P. Rikhvanov², \\ rikhvanov@tpu.ru
}

\author{
Anvar M. Farkhutdinov', \\ anvarfarh@mail.ru \\ 1 Bashkir State University, \\ 32, Validy street, Ufa, 450076, Russia. \\ 2 National Research Tomsk Polytechnic University, \\ 30, Lenin Avenue, Tomsk, 634050, Russia. \\ 3 Institute of Geology Ufa Science Center RAS, \\ 16/2, K. Marks street, Ufa, 450000, Russia. \\ ${ }^{4}$ Research Institute of Safety of Life, \\ 12/1, 8 Marta street, Ufa, 450005, Russia.
}

\author{
Anastasia N. Zlobina ${ }^{1,2}$, \\ anastasiyaz|@mail.ru
}

Rustem A. Ismagilov3,1, rustem_ismagilov@bk.ru

Vladimir N. Nikonov4, nikon-ufa@mail.ru

\section{Larisa N. Belan4,} belan77767@mail.ru

The relevance of the research is caused by the need to study the sources of natural radioactive elements entering drinking water and their areal distribution, as well as the possibility of using carbonate sediments of drinking water (scale) in geochemical and environmental studies. In the Republic of Bashkortostan (Russia), these studies are favoured by different geological structures within the area (mountainous area, foredeep and platform) and variety of rocks of different age and composition (volcanic, igneous, sedimentary, metamorphic), which determines the diversity of the microelement profile of the area.

The aim of the research is to assess the radioactive elements content and spatial distribution in anthropogenic carbonate sediments (drinking water scale).

Object of the research. The data on $U$ and Th content in 467 samples of carbonate deposits (scale) from 267 settlements of the Republic of Bashkortostan was analysed. Samples were taken from various utensils (enamelled and electric kettles, pots, boilers), which is used for boiling water from centralized and individual (wells, streams) water sources.

Methods. The method of instrumental neutron activation analysis based on the research nuclear reactor IRT-T TPU was used to analyse the uranium and thorium content. Data processing was carried out using software packages Statistica 8.0 and Microsoft Excel. The spatial distribution of natural radioactive elements was mapped using ArcGIS 10.2 in the Geostatistical Analyst module using the inverse distance method.

Result. The data obtained allow speaking about uneven distribution of natural radioactive elements $(U, T h)$ in anthropogenic carbonate deposits on the territory of the Republic of Bashkortostan. The average level of the studied chemical elements is characterized by low values of both uranium and thorium. Variations of their content in the studied formations are determined by the combined impact of natural and anthropogenic factors. The regularities of $U$ distribution in scale samples correspond to the geological structure of the territory. Within the platform part, uranium distribution is more uniform than in the mountainous part of the Republic, which reflects the comparative homogeneity of geological and tectonic conditions. According to the results of mapping, four zones of high uranium content in samples of anthropogenic carbonate deposits were identified: Trans-Uralian, Uralian, Western and Southern. In Th spatial distribution there was no clear correlation with the features of the geological structure and metallogeny of the territory. There are three zones: Northern, Central and South-Eastern. Negative anomalies of Th content geographically coinciding with large mining centers are noted. Th/U ratio is characterized by a low value for the whole territory of Bashkortostan - 0,002. At the same time, positive anomalies of this indicator were recorded in the Northern and South-Eastern parts of the Republic, where they are mainly determined by geological component.

\section{Key words:}

Uranium, thorium, man made carbonates, geoecology, thorium-uranium ratio, Republic of Bashkortostan, Southern Urals, geochemistry, radioactive elements, drinking water.

Scientific research was carried out within the program of TPU competitiveness enhancement among the leading research centers.

\section{REFERENCES}

1. Carbonaty: mineralogiya i khimiya [Carbonates: mineralogy and chemistry: translation from english]. Translated from English. Ed. by R.J. Rider. Moscow, Mir Publ., 1987. 496 p.
2. Morse J.W., Arvidson R.S., Luttge A. Calcium carbonate formation and dissolution. Chemical Reviews, 2007, vol. 107, pp. 342-381.

3. Pentecost A. Travertine. Berlin; Heidelberg, Springer-Verlag, 2005. $445 \mathrm{p}$ 
4. Fairchild I.J., Treble P.C. Trace elements in speleothems as recorders of environmental change. Quaternary Science Reviews, 2009, vol. 28, pp. 449-468.

5. Tanner L.H. Continental carbonates as indicators of paleoclimate Developments in Sedimentology, 2010, vol. 62, pp. 179-214.

6. Zhang K.-J., Li Q.-H., Yan L.-L., Zeng L., Lu L., Zhang Y.-X., Hui J., Jin X., Tang X.-C. Geochemistry of limestones deposited in various plate tectonic settings. Earth-Science Reviews, 2017, vol. 167 , pp. 27-46.

7. Soktoev B.R., Rikhvanov L.P., Ilenok S.S., Baranovskaya N.V., Taisaev T.T. Mineralogical-geochemical features of travertines of the modern continental hydrotherms: A G-1 well, Tunka depression, Baikal rift zone. Geology of Ore Deposits, 2015, vol. 57, no. 4 , pp. 331-347.

8. Teboul P.-A., Durlet C., Gaucher E.C., Virgone A., Girard J.-P. Curie J., Lopez B., Camoin G.F. Origins of elements building travertine and tufa: New perspectives provided by isotopic and geochemical tracers. Sedimentary Geology, 2016, vol. 334, pp. 97-114.

9. Ricketts J.W., Ma L., Wagler A.E., Garcia V.H. Global travertine deposition modulated by oscillations in climate. Journal of Quaternary Science, 2019. Available at: https://doi.org/10.1002/ jqs.3144 (accessed 10 November 2019).

10. Rudnick R.L., Gao S. Composition of the continental crust. Treatise on Geochemistry, 2014, vol. 4, pp. 1-51. Available at: https://www.researchgate.net/publication/234288836_Composition _of_the_Continental_Crust_Treatise_Geochem_31-64 (accessed 10 November 2019).

11. Grigoryev N.A. Raspredelenie khimicheskikh elementov $v$ verkhney chasti continentalnoy kory [Distribution of chemical elements in the upper part of the continental crust]. Ekaterinburg, UrO RAN Publ., 2009. $382 \mathrm{p}$.

12. Smyslov A.A. Uran i toriy $v$ zemnoy kore [Uranium and thorium in the earth's crust]. Leningrad, Nauka Publ., 1974. 231 p.

13. Evseeva L.S., Perelman A.I., Ivanov K.E. Geokhimiya urana v zone gipergeneza [Geochemistry of uranium in the hypergenesis zone]. Moscow, Atomizdat Publ., 1974. 278 p.

14. Allègre C.J., Dupré B., Lewin E. Thorium/uranium ratio of the Earth. Chemical Geology, 1986, vol. 56, no. 3-4, pp. 219-227.

15. Wipperfurth S.A., Guo M., Šrámek O., McDonough W.F. Earth's chondritic $\mathrm{Th} / \mathrm{U}$ : negligible fractionation during accretion, core formation, and crust-mantle differentiation. Earth and Planetary Science Letters, 2018, vol. 498, pp. 196-202.

16. Liu H., Zartman R.E., Ireland T.R., Sun W. Global atmospheric oxygen variations recorded by $\mathrm{Th} / \mathrm{U}$ systematics of igneous rocks. Proc. of the National Academy of Sciences of the United States of America, 2019. Available at: https://doi.org/10.1073/pnas. 1902833116 (accessed 10 November 2019).

17. Kamal M.S., Hussein I., Mahmoud M., Sultan A.S., Saad M.A.S Oilfield scale formation and chemical removal: a review. Journal of Petroleum Science and Engineering, 2018, vol. 171, pp. 127-139.

18. Richards C.S., Wang F., Becker W.C., Edwards M.A. A $21^{\text {st }}$ century perspective on calcium carbonate formation in potable water systems. Environmental Engineering Science, 2018, vol. 35, Iss. 3, pp. 143-158

19. Tapkhaeva A.E., Taisaev T.T., Rikhvanov L.P., Yazikov E.G., Baranovskaya N.V. Geochemical specialization of limescale of water sources illustrated by two regions in Siberia. Contemporary Problems of Ecology, 2010, vol. 3, no. 4, pp. 498-507.

20. Soktoev B.R., Rikhvanov L.P., Matveenko I.A. Mineralogical and geochemical characteristics of drinking water salt deposits. IOP Conference Series: Earth and Environmental Science, 2015, vol. 27, Iss. 1, Article 012042.

21. Soktoev B.R., Rihvanov L.P., Arynova Sh.Zh., Baranovskaya N.V Estestvennye radioaktivnye elementy (Th, U) v solevykh otlozheniyakh prirodnykh presnykh vod [Natural radioactive elements (Th, U) in salt deposits of natural fresh water]. Radioaktivnost $i$ radioaktivnye element $v$ srede obitaniya cheloveka. Materialy V Mezhdunarodnoy konferentsii [Radioactivity and radioactive elements in the human environment: proceedings of the V International conference]. Tomsk, STT Publ., 2016. pp. 599-603.

22. Nikonov V.N. Prirodnaya i tekhnogennaya radioaktivnost Respubliki Bashkortostan [Natural and technogenic radioactivity of the Republic of Bashkortostan]. Uralskiy ekologicheskiy vestnik, 2012, vol. 2 (31), pp. 23-30
23. Belan L.N. Geoekologicheskie osnovy prirodno-tekhnogennykh ekosistem gornorudnykh rayonov Bashkortostana. Avtoreferat Diss. Dokt. nauk [Geoecological bases of natural and technogenic ecosystems of mining regions of Bashkortostan. Dr. Diss. Abstarct]. Moscow, 2007. $50 \mathrm{p}$.

24. Asylbaev I.G. Otsenka geokhimicheskogo sostoyaniya pochv Yuzhnogo Urala. Avtoreferat Diss. Dokt. nauk [Assessment of the geochemical state of soils in the southern Urals. Dr. Diss. Abstarct]. Ufa, 2016. $44 \mathrm{p}$.

25. Opekunova M.G., Somov V.V., Papyan E.E. Soil contamination in the impact zone of mining enterprises in the Bashkir Transural region. Eurasian Soil Science, 2017, vol. 50, pp. 732-745.

26. Rikhvanov L.P., Yazikov E.G., Baranovskaya N.V., Yankovich E.P. Sposob opredeleniya uchastkov zagryazneniya uranom okruzhayushchey sredy [The method of determining areas of uranium contamination of the environment]. Patent RF, no. 2005120840, 2007.

27. Witkowska E., Szczepaniak K., Biziuk M. Some applications of neutron activation analysis: a review. Journal of Radioanalytical and Nuclear Chemistry, 2005, vol. 265, pp. 141-150.

28. Sudyko A.F. Opredelenie urana, toriya, skandiya i nekotorykh redkozemelnykh elementov $\mathrm{v}$ dvadtsati chetyrekh standartnykh obrazcakh sravneniya instrumentalnym neytronno-aktivatsionnym metodom [Determination of uranium, thorium, scandium and some rare earth elements in twenty-four standard samples of comparison by instrumental neutron activation method]. Radioaktivnost $i$ radioaktivnye element $v$ srede obitaniya cheloveka. Materialy $V$ Mezhdunarodnoy konferentsii [Radioactivity and radioactive elements in the human environment. Proc. of the V International conference]. Tomsk, STT Publ., 2016. pp. 620-624.

29. Krinochkin L.A., Shkarin A.B. Sostavlenie geohimicheskikh osnov masshtaba 1:1000000 listov $N-40,41,42, \quad P-45,52,55,57$, $O-38,55,56$ [Compilation of geochemical foundations scale 1:1000 000 sheets N-40,41,42, P-45,52,55,57, O-38,55,56]. Moscow, Rosgeolfond Publ., 2011. 178 p.

30. Kamaletdinov M.A. Novaya geologiya (teoriya sharyazhey) [New Geology (thrust-nappe theory)]. Geologiya. Izvestiya Otdeleniya nauk o Zemle i prirodnykh resursov Akademii nauk Respubliki Bashkortostan, 1998, no. 3, pp. 10-23.

31. Farkhutdinov I.M., Ismagilov R.A., Farkhutdinov A.M., Farkhutdinova L.M. Murat Kamaletdinov and the struggle for acceptance of the thrust-nappe theory. Earth Sciences History, 2017, vol. 36 , no. 1, pp. 101-115.

32. Minigazimov N.S. Okhrana i ratsionalnoe ispolzovanie vodnykh resursov $v$ neftyanoy promyshlennosti. Avtoreferat Diss. Dokt nauk [Protection and rational use of water resources in the oil industry. Dr. Dis. Abstract]. Ekaterinburg, 2000. 45 p.

33. Kontar E.S. Geologo-promyshlennye tipy mestorozhdeniy medi, tsinka, svintsa na Urale (geologicheskie usloviya razmeshcheniya, istoriva formirovaniya, perspektivy) [Geological and industrial types of copper, zinc, lead deposits in the Urals (geological conditions of placement, history of formation, prospects)]. Ekaterinburg, UGGU Publ., 2013. 199 p.

34. Volkov A.V., Novikov I.A., Razumovskiy A.A., Murashov K.Yu., Sidorova N.V. Geochemical features and formation conditions of of the cupriFerous sandstones of the Orenburg pre-Urals. Lithosphere, 2018, vol. 18, no. 4, pp. 593-606. In Rus.

35. Arbuzov S.I., Volostnov A.V., Rikhvanov L.P., Mezhibor A.M., Ilenok S.S. Geochemistry of radioactive elements $(\mathrm{U}, \mathrm{Th})$ in coal and peat of northern Asia (Siberia, Russian Far East, Kazakhstan, and Mongolia). International Journal of Coal Geology, 2011, vol. 86, pp. 318-328.

36. Chen J., Chen P., Yao D., Huang W., Tang S., Wang K., Liu W., Hu Y., Zhang B., Sha J. Abundance, distribution, and modes of occurrence of uranium in Chinese coals. Minerals, 2017, vol. 7, Iss. 12, Article 239.

37. Lauer N., Vengosh A., Dai S. Naturally occurring radioactive materials in uranium-rich coals and associated coal combustion residues from China. Environmental Science and Technology, 2017, vol. 51, pp. 13487-13493.

38. Dai S., Yan X., Ward C.R., Hower J.C., Zhao L., Wang X., Zhao L., Ren D., Finkelman R.B. Valuable elements in Chinese coals: a review. International Geology Review, 2018, vol. 60, pp. 590-620. 
39. Parzentny H.R., Rog L. The role of mineral matter in concentrating uranium and thorium in coal and combustion residues from power plants in Poland. Minerals, 2019, vol. 9, Iss. 5, Article 312.

40. Gosudarstvenny doklad o sostoyanii prirodnykh resursov i okruzhayushchey sredy Respubliki Bashkortostan v 2004 godu [State report on the state of natural resources and environment of the Re- public of Bashkortostan in 2004]. Ufa, Natural resources Ministry Publ., 2004. 306 p.

Received: 14 November 2019.

\section{Information about the authors}

Iskhak M. Farkhutdinov, Cand. Sc., head of geological department, Bashkir State University.

Bulat R. Soktoev, Cand. Sc., associate professor, National Research Tomsk Polytechnic University.

Leonid P. Rikhvanov, Dr. Sc., professor, National Research Tomsk Polytechnic University.

Anvar M. Farkhutdinov, Cand. Sc., associate professor, Bashkir State University.

Anastasia N. Zlobina, assistant professor, Bashkir State University; post-graduate student, National Research Tomsk Polytechnic University.

Rustem A. Ismagilov, Cand. Sc., senior researcher, Institute of Geology Ufa Science Center RAS; associate professor, Bashkir State University.

Vladimir N. Nikonov, Cand. Sc., senior researcher, Research Institute of Safety of Life.

Larisa N. Belan, Dr. Sc., director, Research Institute of Safety of Life. 